\title{
Analisis Faktor Keberadaan Vektor Penular DBD melalui Identifikasi Tempat Potensial Perkembangbiakan Nyamuk Aedes Sp. di Desa Gergunung, Kabupaten Klaten, Jawa Tengah
}

\author{
Nur Alvira Pascawati ${ }^{*}$ Elisabeth Deta ${ }^{*}$, Ellen Petra Songjanan ${ }^{*}$, Tri Baskoro Tunggul Satoto ${ }^{* *}$ \\ * Program Studi S-1 Kesehatan Masyarakat, Universitas Respati Yogykarta, \\ ** Ilmu Kedokteran Tropis, Universitas Gadjah Mada \\ email:irha011185@yahoo.com
}

\section{ABSTRACT}

The presence of potential breeding places can be used to measure the risk of DHF transmission in Klaten. This result can be used by the community to eradication of mosquito breeding place on target and can improve to early warning system through effective methods for vector control. Type of study was analytic with cross-sectional study. The study was conducted in 104 households with simple random sampling technique. Data analysis used three stages: univariate, bivariate (Chi-square, Kolmogorov Smirnov, Spearman rank) and multivariate test with $\alpha=5 \%$. The density of larvae based on the value of CI, HI, and BI amounted to $1.6 \%$, $19.2 \%, 27.9 \%$. The potential place for larvae breed based on Maya Index of $76 \%$. Containers of open wells with groundwater sources, the volume of water is more than 1 liter and the material from cement can be the preferred place for mosquitoes to breed. Multivariate analysis shows that open wells are strongly related and has a risk of 1,556 (CI: 1,199-2,019) increasing the density of larvae compared with other variables.The density of larvae based on BI is a high category, HI is a moderate category and CI is a low category. This condition is influenced by the presence of open wells made of cement and can hold water in large quantities. Improve to early warning system of DHF transmission through identification of the presence of potential breading places in this area are to close the wells at the household level and conduct regular monitoring on the Controllable Sites.

Keywords: Potential, Breeding Place, Aedes sp, DHF

\section{PENDAHULUAN}

Demam Berdarah Dengue sudah tersebar di seluruh dunia termasuk tiga negara anggota wilayah WHO yakni Amerika (PAHO), Asia Tenggara (SEARO) dan Pasifik Barat (WPRO). ${ }^{1}$ Indonesia merupakan salah satu negara anggota SEARO yang selama tahun 1990-2015 sebagai penyumbang pertama masalah DBD berdasarkan Incidence Rate (IR) dan Case Fatality Rate(CFR). ${ }^{2}$ Pada tahun 2016, IR DBD di Indonesia mencapai 77,96/100.000 penduduk dan CFR sebesar 0,79. Angka ini sangat tinggi jika dibandingkan tahun sebelumnya yakni 50,83/100.000 penduduk dan masih sangat jauh dari target nasional yaitu $<49 / 100.000$ penduduk. $^{3}$

Jawa Tengah, merupakan salah satu provinsi di Indonesia yang memiliki masalah serius penyakit DBD karena kasus ini telah menyebar di 35 
kabupaten dengan jumlah kasus yang terus mengalami peningkatan. Pada tahun 2015 kasus DBD mengalami peningkatan dan berada di atas target nasional dibandingkan tahun sebelumnya mencapai 47,9 per 100.000 penduduk. $^{4}$

Berdasarkan data kasus DBD di Dinas Kesehatan Kabupaten Klaten diperoleh nilai insidance rate (IR) pada tahun 2015 sebesar 45,22 per 100.000 penduduk dengan Case Fatality Rate (CFR) mencapai $4,77 \% .^{5}$ Nilai IR menujukkan kasus DBD di Kabupaten Klaten termasuk dalam kategori sedang (25-49 per 100.000 penduduk) dan CFR menunjukkan angka kematian berada diatas target Nasional yaitu $<1 \%{ }^{3}$. Kasus DBD di Kabupaten Klaten yang tertinggi dan termasuk dalam kategori endemis adalah Desa Gergunung dengan jumlah penderita tahun 2016 mencapai 69 orang. ${ }^{6}$

Penyakit DBD memiliki kompkesitas yang tinggi karena dipengaruhi oleh beberapa faktor yaitu perubahan lingkungan, populasi profil imunologi dan transmisi terhadap wabah DBD menunjukkan pola spasial dan temporal inheren dinamis. Prediktor yang memiliki sifat non-homogen dan tidak stabil dalam distribusi akan mempersulit anggapan bahwa perubahan epidemiologi sebagai faktor tunggal. ${ }^{7}$

Perubahan faktor risiko pada tempat potensial perkembangbiakan Aedes sp sebagai vektor penular penyakit DBD jika tidak diikuti dengan penerapan sistem kewaspadaan dini yang maksimal di lapangan maka akan berdampak pada penularan dan Kejadian Luar Biasa (KLB). Kondisi ini dapat diamati dari laporan Angka Bebas Jentik (ABJ) di Indonesia yang sering mengalami fluktuasi, nilai $A B J$ yang belum mencapai taget nasional sebesar 95\%, ABJ di tiap wilayah mengalami disparitas yang cukup besar dan terjadi ketidaksesuaian antara $\mathrm{ABJ}$ dan tingginya kasus $\mathrm{DBD}^{8}$.

Penanggulangan penyakit DBD diutamakan pada pemutusan rantai penularan melalui pengendalian tempat perkembangbiakan nyamuk Aedes spp. Kegiatan untuk mencegah perkembangbiakan vektor adalah membasmi nyamuk saat berada pada stadium jentik dan pupa dengan Pemberantasan Sarang Nyamuk (PSN) yang menuntut peran serta masyarakat dalam pelaksanaannya. ${ }^{9}$ Kegiatan ini lebih banyak dititikberatkan pada penutupan dan abatisasi pada bak mandi serta penguburan barang-barang bekas di sekitar rumah yang berpeluang menampung air hujan, sedangkan tempat potensial lain belum mendapatkan perhatian yang maksimal. Kondisi ini sesuai dengan pernyataan Nugrahaningsi et al bahwa salah satu faktor lingkungan yang berkontribusi terhadap keberadaan jentik adalah keberadaan container. ${ }^{10}$

Tempat perkembangbiakan nyamuk Aedes spp yang bersifat lokal spesifik menujukkan bahwa setiap daerah memiliki perbedaan tempat yang disukai oleh nyamuk dengan mempertimbangkan faktor-faktor lingkungan fisik (cuaca/iklim, pemukiman tempat perkembangbiakan), lingkungan sosial-budaya dan aspek vektor $^{11}$. Karakteristik tempat perkembangbiakan nyamuk dapat dipengaruhi oleh jenis, bahan dasar, letak, warna dan volume container. ${ }^{12-14}$ Penelitian yang dilakukan oleh Sari et al menujukkan bahwa jenis kontainer yang banyak ditemukan jentik adalah bak mandi dan ban bekas, berbahan dasar plastik dan semen yang didominasi 
warna merah. ${ }^{12}$ Penelitian Ambarito et al menjelaskan bahwa volume kontainer berhubungan erat dengan keberadaan nyamuk pra dewasa.

Keberadaan kontainer dapat digunakan untuk melihat apakah suatu wilayah beresiko tinggi terhadap penularan DBD melalui tempat perkembangbiakan larva. Tempat-tempat tersebut dapat dibedakan menjadi Controllable Site (CS) dan Disposible Site (DS) dan dianalisis dengan indiaktor Maya Index (MI) serta menentukan kepadatan larva berdasarkan indikator CI, BI, dan HI. ${ }^{15-16}$ Hasil penelitian Purnama dan Baskoro bahwa penderita DBD tertinggi banyak ditemukan pada rumah yang memiliki jenis kontainer controllable sites (CS) berupa bak mandi dan jenis disposible sites (DS) terdapat pada ban bekas. ${ }^{14}$ Faktor abiotik meliputi curah hujan dan temperatur serta faktor biotik meliputi predator, parasit kompetitor dan makanan dalam kontainer dapat mempengaruhi siklus hidup nyamuk Aedes aegypti berupa kegagalan telur dan pupa menjadi imago. Selain faktor tersebut bentuk, ukuran, letak kontainer, ada tidaknya penutup kontainer juga mempengaruhi kualitas hidup nyamuk. ${ }^{17}$

Berdasarkan pada kondisi tersebut maka tim peneliti melakukan studi pendahuluan di Desa Gergunung untuk memberikan gambaran awal mengenai banyaknya kontainer yang digunakan oleh masyarakat lokal menujukkan bahwa beberapa rumah memiliki sumber air tanah yang berasal dari sumur, jenis kontainter berupa bak mandi yang terbuat dari plastik, tanpa penutup, berwarna gelap dan memiliki volume 1-20 liter.

Dari pengamatan tersebut diperlukan penelitian mendalam untuk melakukan analisis faktor yang berpotensi terhadap keberadaan vektor DBD melalui identifikasi tempat petensial nyamuk Aedes spp. Output dari penelitian ini dapat memberikan masukan untuk meningkatkan sistem kewaspadaan dini bagi masyarakat dan puskesmas melalui kegiatan PSN yang efektif dan efisien berdasarkan karakteritik kontainer di suatu wilayah.

\section{METODE PENELITIAN}

Penelitian ini merupakan jenis penelitian kuantitatif dengan desain cross-sectional. Penelitian dilaksanakan di Desa Gergunung dengan mengobservasi 104 rumah dan 1.832 kontainer. Penetapan jumlah rumah sebagai sampel menggunakan tehnik simple random sampling dengan rumus besar sampel dari Lameshow dan Lwanga untuk penelitian hypothesis test for two population proportions (two-sided test $)^{18}$, menggunakan kekuatan uji $(1-\beta)=95 \%$ dengan tingkat kemaknaan $(\alpha)=0,05$. Variabel yang diukur adalah tipe kontainer, letak kontainer, keberadaan penutup, volume, bahan, sumber air kontainer dan indikator entomologi berupa CI, HI, BI dan MI.

Tahapan penelitian ini dimulai dari: 1) Melakukan observasi karakteristik seluruh kontainer di rumah responden. Observasi di sumur dengan pemasangan funnel trap menggunakan pedoman dari Gionar 2011; 2) Survei dan pengambilan jentik di dalam kontainer menggunakan metode single larva, yaitu: mengambil satu jentik di setiap tempat genangan air yang ditemukan jentik untuk diidentifikasi lebih lanjut berdasarkan pedoman dari Kemenkes RI 2011; 3) Identifikasi jentik di laboratorium Universitas Respati Yogyakarta menggunakan pedoman 
koleksi spesimen dan data yang dikeluarkan oleh Kemenkes RI 2017. ${ }^{19-21}$

Instrument yang digunakan oleh tim peneliti adalah: 1) Form observasi yang dimodifikasi dari panduan Kemenkes RI $2017^{21}$; 2) Alat untuk mengambil larva di sumur dengan funnel trap; 3) Alat untuk mengukur volume kontainer dengan meteran; 4) Alat untuk pengambilan jentik pada kontainer kecil dengan cidukan, senter, pipet dan plastik zipper/vial bottle; 5) Alat untuk identifikasi kunci jentik menggunakan mikroskop dengan pembesaran 100 kali dan 6) Identifikasi kunci jentik oleh laboran terlatih dan berpedoman pada buku Kemenkes RI 2017.

Data hasil survei entomologi akan dianalisis data menggunakan uji univariat dengan distribusi frekuensi, uji bivariat dengan Chi-square, Fisher Exact, Kolmogorov Smirnov and Spearman rank dan uji multivariat dengan regresi logistik berganda dengan $\alpha=5 \%$.

\section{HASIL DAN PEMBAHASAN}

\section{Kepadatan Larva dengan Indikator CI, HI, BI}

Hasil pengukuran keberadaan larva dengan indikator HI sebesar 19,2\% yang berdasarkan tabel density figure ${ }^{22}$ termasuk dalam resiko penularan sedang (skala 4), CI sebesar $1,6 \%$ berada dalam kategori rendah (skala 1) dan BI sebesar $27,9 \%$ berada dalam kategori sedang (skala 4).

Indeks kepadatan jentik di Desa Gergunung tercatat dengan nilai CI 1,6\%; HI 19,2\%; dan BI 27,9\%. Berdasarkan indeks entomologi ini, maka desa Gergunung dinyatakan termasuk kedalam kategori penularan sedang. Container Index (CI) menggambarkan banyaknya banyak kontainer sebagai tempat perkembangbiakan larva Aedes spp. House Index (HI) menggambarkan penyebaran nyamuk disuatu wilayah. Menurut standar World Health Organization (WHO), suatu daerah dianggap berisiko tinggi terhadap penyebaran penyakit DBD apabila $\mathrm{HI}>10 \%$, sedangkan berisiko rendah $\mathrm{HI}<1 \%{ }^{15}$.

Nilai HI di wilayah ini lebih tinggi dari standar WHO, sehingga menunjukan bahwa masih banyak rumah yang positif jentik dan cukup tingginya penyebaran nyamuk Aedes spp. di daerah tersebut sehingga dapat menyebabkan risiko terjadinya penularan DBD. Breteaux Index (BI) adalah banyaknya penampungan air yang positif per 100 rumah yang diperiksa. BI merupakan index yang paling baik untuk memperkirakan kepadatan vektor karena menyatukan rumah maupun kontainer. ${ }^{24}$ Nilai BI berdasarkan parametar entomologis memang lebih rendah dibandingkan standar WHO (>50\%), namun angka $27,9 \%$ hampir mendekati standar minimal yang di tetapkan WHO sehingga tetap perlu diturunkan melalui kegiatan PSN yang tepat sasaran.

\section{Tempat Perkembangbiakan Nyamuk Aedes spp berdasarkan Indikator Maya Indeks}

Analisa maya indeks dilakukan untuk mengetahui tingkat resiko penularan di suatu wilayah melalui tempat potensial perkembangbiakan Nyamuk Aedes spp. Maya indeks diperoleh berdasarkan hasil perhitungan Breeding Risk Index (BRI) dan Hygiene Risk Index (HRI). BRI diperoleh dari hasil identifikasi Controllable Site (CS) dan HRI diperoleh dari hasil identifikasi Disposible Site $(D S)^{23}$, seperti pada tabel 1 berikut: 
Tabel 1. Distribusi Controllable Site dan Disposible Site di Desa Gergunung

\begin{tabular}{|c|c|c|c|c|c|c|c|}
\hline \multirow[t]{2}{*}{ No } & \multirow[t]{2}{*}{ Jenis Kontainer } & \multicolumn{4}{|c|}{ Status Keberadaan Jentik } & \multicolumn{2}{|c|}{ Total } \\
\hline & & \multicolumn{2}{|c|}{ Ada } & \multicolumn{2}{|c|}{ Tidak Ada } & & \\
\hline 1 & Controlable Site & $\mathrm{n}$ & $\%$ & $\mathrm{n}$ & $\%$ & $\mathrm{n}$ & $\%$ \\
\hline & Bak Mandi & 16 & 16,7 & 80 & 83,3 & 96 & 12,6 \\
\hline & Bak WC & 0 & 0 & 22 & 100 & 22 & 2,9 \\
\hline & Drum & 0 & 0 & 2 & 100 & 2 & 0,3 \\
\hline & Tempayan & 2 & 18,2 & 9 & 81,8 & 11 & 1,4 \\
\hline & Ember & 8 & 2,5 & 318 & 97,5 & 326 & 42,8 \\
\hline & Tempat Minum Burung & 0 & 0 & 41 & 100 & 41 & 5,4 \\
\hline & Penampungan Dispenser & 1 & 5,6 & 17 & 94,4 & 18 & 2,4 \\
\hline & Penampungan Kulkas & 0 & 0 & 35 & 100 & 35 & 4,6 \\
\hline & Talang Air & 0 & 0 & 0 & 0 & 0 & 0 \\
\hline & Kolam Ikan & 0 & 0 & 1 & 100 & 1 & 0,1 \\
\hline & Sumur & 2 & 8 & 23 & 92 & 25 & 3,3 \\
\hline & Kendi & 0 & 0 & 185 & 100 & 185 & 24,8 \\
\hline \multirow[t]{7}{*}{2} & Disposible Site & $\mathrm{n}$ & $\%$ & $\mathrm{n}$ & $\%$ & $\mathrm{n}$ & $\%$ \\
\hline & Tatakan Vas & 0 & 0 & 804 & 100 & 804 & 75,1 \\
\hline & Gelas/Botol & 0 & 0 & 23 & 100 & 23 & 2,1 \\
\hline & Ban Bekas & 0 & 0 & 62 & 100 & 62 & 5,8 \\
\hline & Kaleng & 0 & 0 & 47 & 100 & 47 & 4,4 \\
\hline & Botol Bekas & 0 & 0 & 51 & 100 & 51 & 4,7 \\
\hline & Ember Bekas & 0 & 0 & 83 & 100 & 83 & 7,8 \\
\hline
\end{tabular}

Tabel 1 menunjukkan karateritik jenis CS yang digunakan oleh sebagian besar masyarakat di Desa Gergunung adalah ember dan jenis DS yang ditemukan di rumah responden adalah tatakan vas, namun penemuan jentik tertinggi ditemukan pada CS dengan jenis bak mandi.

Observasi kontainer dalam penelitian ini ditemukan 1.832 kontainer di 104 rumah sampel dan sebagian besar merupakan kontainer berjenis DS, namun penemuan jentik lebih banyak ditemukan pada kontainer berjenis CS yaitu bak mandi, sebesar 16,7\%. Hasil serupa juga ditemukan pada penelitian yang dilakukan oleh Ramadhani dan Astuty di Jakarta Pusat serta
Sari et al di Sekolah Dasar, dengan penemuan larva tertinggi ditemukan pada jenis bak mandi. ${ }^{25,12}$. Penemuan larva pada kontainer yang berjenis bak mandi sebenarnya mudah untuk dikendalikan karena ini adalah jenis kontainer yang selalu terpantau dan air di dalam kontainer digunakan sehari-hari oleh anggota kelaurga, sehingga diperlukan adanya peningkatan pemahaman dan perilaku PSN yang tepat sasaran di masyarakat secara berkelanjutan.

Hasil identifikasi jenis kontainer dilanjutkan dengan menghitung nilai HRI dan BRI untuk mengetahui tingkat risiko penularan dan kebersihan Desa Gergunung seperti yang tergambar pada tabel 2, berikut:

Tabel 2. Matrix 3x3 komponen Breeding Risk Indicator (BRI) dan Hygiene Risk Indicator (HRI)

\begin{tabular}{rccc}
\hline Kategori & BRI 1(Rendah) & BRI 2 (Sedang) & BRI 3 (Tinggi) \\
\hline HRI 1 (Rendah) & $0(0,0 \%)$ & $0(0,0 \%)$ & $0(0,0 \%)$ \\
HRI 2 (Sedang) & $24(24,0 \%)$ & $52(52,0 \%)$ & $10(10,0 \%)$ \\
HRI 3 (Tinggi) & $1(1,0 \%)$ & $10(10,0 \%)$ & $17(17,0 \%)$ \\
\hline
\end{tabular}


Tabel 2 menunjukkan bahwa sebagian besar rumah di Desa Gergunung memiliki status maya index sedang sejumlah 52 rumah (52\%) karena memenuhi kriteria risiko penularan sedang dengan tingkat kebersihan cukup rendah (HRI 2/BRI 2).

Hasil analisis dari perhitungan MI di Desa Gergunung berada dalam kategori sedang. Dua kondisi yang berpengaruh adalah keberadaan tempat potensial bagi perkembangbikan larva Aedes $s p$ ditunjukkan pada kontainer berjenis CS dan kebersihan suatu wilayah ditujukkan pada kontainer berjenis $\mathrm{DS}^{26}$. Jumlah CS yang cukup tinggi menunjukkan bahwa Desa Gergunung memiliki risiko menjadi wilayah yang berpotensi dalam menyediakan tempat bagi perkembangbiakan larva Aedes spp.

Potret lain dari Desa Gergunung berdasarkan analisis MI menunjukkan bahwa desa ini memiliki sanitasi lingkungan yang cukup buruk dan berpotensi tinggi sebagai tempat potensial perkembangbiakan Aedes spp. Kondisi ini memiliki persaman dengan penelitian yang dilakukan oleh Prasetyo dan Ginanjar yang menyatakan bahwa maya index di masyarakat termasuk dalam kategori sedang, hal tersebut dipengaruhi oleh tingginya kontainer dengan tipe controllable site dan disposible site. ${ }^{15}$
Hasil observasi di lapangan menujukkan bahwa BRI yang sedang diakibatkan banyaknya penggunaan kontainer dengan tipe controllable site karena alasan kebutuhan sehari-sehari masyarakat yang tidak dipengaruhi oleh musim seperti mandi, memasak, dan mencuci, misalnya kontainer dengan jenis ember. Nilai HRI yang sedang disebabkan karena banyaknya kontainer dengan tipe disposible site yang ditemukan di lingkungan masyarakat seperti tatakan vas, namun tidak ditemukan jentik karena keberadaan air pada jenis kontainer DS sangat dipengaruhi oleh musim dan saat penelitian ini berlangsung kondisi kontainer ini tidak terisi air.

\section{Karakteristik Kontainer yang berhubungan dengan Kepadatan Larva Aedes spp. \\ Hasil observasi dari karakteristik kontainer yang dimiliki masyarakat Desa Gergunung seperti tipe, volume, keberadaan penutup, letak, warna, bahan dan sumber air yang disukai oleh nyamuk untuk berkembangbiak, dapat dilihat pada tabel 3, berikut:}

Tabel 3. Karakterisrtik Kontainer

\begin{tabular}{|c|c|c|c|c|c|c|c|c|}
\hline \multirow{3}{*}{ Karakteristik Kontainer } & \multicolumn{4}{|c|}{ Status Kepadatan Larva } & \multirow{2}{*}{\multicolumn{2}{|c|}{ Total }} & \multirow{3}{*}{ P- Value } & \multirow[t]{3}{*}{$\mathrm{C}$} \\
\hline & \multicolumn{2}{|c|}{ Positif(+) } & \multicolumn{2}{|c|}{ Negatif (-) } & & & & \\
\hline & $\mathrm{n}$ & $\%$ & $\mathrm{n}$ & $\%$ & $\mathrm{n}$ & $\%$ & & \\
\hline \multicolumn{9}{|l|}{ Tipe } \\
\hline a. Controllable Site (CS) & 29 & 3,8 & 733 & 96,2 & 762 & 100 & 0,000 & 0,149 \\
\hline b. Disposible Site (DS) & 0 & 0,0 & 1070 & 100 & 1070 & 100 & & \\
\hline \multicolumn{9}{|l|}{ Volume Kontainer } \\
\hline a. $<1 \mathrm{~L}$ & 6 & 0,5 & 1241 & 99,5 & 1247 & 100 & 0,000 & 0,141 \\
\hline b. $\quad 1 \mathrm{~L}-20 \mathrm{~L}$ & 10 & 2,7 & 362 & 97,3 & 372 & 100 & & \\
\hline c. $20 \mathrm{~L}-100 \mathrm{~L}$ & 10 & 5,7 & 165 & 94,3 & 175 & 100 & & \\
\hline d. $>100 \mathrm{~L}$ & 3 & 7,9 & 35 & 92,1 & 38 & 100 & & \\
\hline \multicolumn{9}{|l|}{ Keberadaan Penutup } \\
\hline \multicolumn{9}{|l|}{ Kontainera. } \\
\hline a. Ada & 4 & 2,3 & 167 & 97,7 & 171 & 100 & 0,340 & 0,119 \\
\hline b. Tidak Ada & 25 & 1,5 & 1636 & 98,5 & 1661 & 100 & & \\
\hline
\end{tabular}




\begin{tabular}{lllllllll}
\hline Letak Kontainer & & & & & & & & \\
a. Di dalam rumah & 23 & 3,5 & 630 & 96,5 & 653 & 100 & 0,000 & 0,115 \\
b. Di luar rumah & 6 & 0,5 & 1173 & 99,5 & 1179 & 100 & & \\
\hline Warna Kontainer & 17 & 1,4 & 1241 & 98,6 & 1258 & 100 & 0,927 & 0,037 \\
a. Gelap & 12 & 2,2 & 524 & 97,8 & 536 & 100 & & \\
b. Terang & 0 & 0,0 & 38 & 100,0 & 38 & 100 & & \\
c. Bening & & & & & & & & \\
\hline Bahan Kontainer & 4 & 2,5 & 155 & 97,5 & 159 & 100 & 0,187 & 0,056 \\
a. Semen & 0 & 0,0 & 240 & 100,0 & 240 & 100 & & \\
b. Tanah Liat & 17 & 1,3 & 1276 & 98,7 & 1293 & 100 & & \\
c. Plastik & 0 & 0,0 & 2 & 100,0 & 2 & 100 & & \\
d. Kaca & 7 & 10,3 & 61 & 89,7 & 68 & 100 & & \\
e. Keramik & 0 & 0,0 & 62 & 100,0 & 62 & 100 & & \\
f. Karet & 1 & 12,5 & 7 & 87,5 & 8 & 100 & & \\
g. Ubin & & & & & & & & \\
\hline Sumber Air Kontainer & 3 & 2,2 & 131 & 97,8 & 134 & 100 & 0,000 & 0,153 \\
a. PAM & 10 & 5,6 & 167 & 94,4 & 177 & 100 & & \\
b. Sumur Terbuka & 15 & 3,3 & 434 & 96,7 & 449 & 100 & & \\
c. Sumur Pompa & 1 & 0,1 & 1071 & 99,9 & 1072 & 100 & & \\
d. Air Hujan & & & & & & &
\end{tabular}

Berdasarkan hasil analisis bivariate ditemukan bahwa karakteristik kontainer yang dapat menjadi tempat potensial bagi vektor penular DBD di Desa Gergunung adalah tipe container yang berjenis CS, volume container 20-100 L, letak container di dalam rumah dan sumber air yang berasal dari sumur terbuka dengan nilai $p$ value $=0,000(p<0,05)$.

Tempat Potensial Vektor DBD yang berhubungan dengan kepadatan vektor adalah tipe kontainer, letak kontainer, volume kontainer, dan sumber air kontainer. Kontainer dengan tipe Controllale Site memiliki persentase keberadaan jentik tertinggi, sehingga dinyatakan berisiko sebagai tempat perkembangbiakan larva Aedes spp dan mempercepat penularan DDB. $^{27}$ Volume kontainer yang paling berkontribusi untuk meningkatkan kepadatan larva adalah 1 - 20 liter dan > 20 - $100 \mathrm{~L}$.

Nyamuk Aedes spp sangat menyukai tempat yang memiliki jumlah air yang banyak dan tenang seperti bak mandi dan volume kontainer yang besar berpotensi sebagai tempat berkembangbiaknya larva, karena akan sulit dibersihkan apabila terisi air. ${ }^{28-29}$ Letak kontainer yang berada di dalam rumah lebih banyak ditemukan jentik dibandingkan dengan kontainer yang berada di luar rumah. Nyamuk Aedes aegpty lebih menyukai kontainer yag berada di suasana yang gelap dan tenang yang terletak di dalam rumah. ${ }^{30}$

Bahan kontainer dengan penemuan larva tertinggi terdapat pada kontainer yang berbahan semen. Hasil ini sejalan dengan penelitian yang dilakukan oleh Sari, et al bahwa kontainer berbahan semen, banyak ditemukan jentik karena kontainer berbahan ini sulit dibersihkan dan permukaan yang kasar membuat jentik lebih mudah mendapatkan makanan dan meletakkan telurnya. $^{12,31}$ Sumber air kontainer yang memiliki persentase paling besar adalah sumur terbuka dan berbahan semen. Penelitian ini didukung dengan penelitian Agustina \& Kartini bahwa kontainer yang memiliki persentase terbesar adanya jentik adalah sumur. ${ }^{30}$

Karakteritik Tempat Potensial yang Dominan terhadap Kepadatan Larva Aedes spp.

Hasil analisis tabel 4 menunjukkan bahwa sumber air dari sumur terbuka, berbahan semen dan bervolume 20-100 L dinyatakan berisiko terhadap tingginya 
kepadatan larva Aedes spp di Desa Gergunung.

Tabel 4. Permodelan Multivariat

\begin{tabular}{|c|c|c|c|c|c|c|}
\hline \multirow[t]{2}{*}{ Model } & \multirow[t]{2}{*}{ B } & \multirow[t]{2}{*}{ Wald } & \multirow[t]{2}{*}{ Sig } & \multirow[t]{2}{*}{$\operatorname{Exp}(B)$} & \multicolumn{2}{|c|}{$95 \%$ CI for $\operatorname{Exp}(B)$} \\
\hline & & & & & Lower & Upper \\
\hline $\begin{array}{l}\text { Volume } \\
\text { Kontainer }\end{array}$ & $-0,689$ & 10,354 & 0,001 & 0,506 & 0,334 & 0,766 \\
\hline Bahan Kontainer & $-0,306$ & 3,883 & 0,049 & 0,736 & 0,543 & 0,998 \\
\hline $\begin{array}{l}\text { Sumber Air } \\
\text { Kontainer }\end{array}$ & 0,442 & 11,043 & 0,001 & 1,556 & 1,199 & 2.019 \\
\hline Constant & 4,791 & 29,703 & 0,000 & 120,467 & & \\
\hline
\end{tabular}

Hasil analisis multivariat menunjukkan bahwa faktor yang dominan mempengaruhi kepadatan larva di Desa Gergunung adalah sumur yang terbuka dengan bahan semen dan memiliki volume air yang lebih besar.

Risiko tingginya keberadaan larva di dalam sumur sebesar 1,199-2,019 kali lebih besar jika dibandingkan dengan karaktertik kontainer lain. Sumur yang ditemukan di rumah masyarakat berada di dalam dan luar rumah namun terletak di bawah pohon yang terlindung dari sinar matahari. Kondisi ini mengakibatkan kurangnya cahaya dan kelembaban tinggi di dalam kontainer, sehingga nyamuk merasa aman dan tenang untuk bertelur. Keadaan lain menujukkan bahwa seluruh sumur yang dimiliki masyarakat dalam kondisi yang terbuka karena selalu digunakan untuk kebutuhan sehari-hari, sehingga mempermudah nyamuk dalam meletakkan telurnya. ${ }^{31}$ Penelitian ini sesuai dengan hasil yang diungkapkan Palupi bahwa sumur gali yang terbuka lebih disukai nyamuk sebagai tempat perindukan. ${ }^{32}$ Buku pedoman Kemenkes 2017 juga menyebutkan bahwa nyamuk betina tertarik untuk meletakkan telurnya pada kontainer air yang terbuka, berwarna gelap dan terlindung dari sinar matahari.

\section{KESIMPULAN}

Risiko penularan DBD berdasarkan tingkat kepadatan vektor di Desa Gergunung termasuk dalam kategori sedang dan berdasarkan hasil analisis MI menunjukkan bahwa desa ini memiliki sanitasi lingkungan yang cukup buruk dan berpotensi menyediakan tempat potensial perkembangbiakan Aedes spp. Hasil analisis faktor yang berpotensi terhadap keberadaan vektor DBD melalui identifikasi tempat petensial nyamuk Aedes spp adalah sumur yang terbuka dengan bahan semen dan memiliki ukuran besar. Untuk mengeliminasi kondisi tesebut diperlukan gerakan 1 rumah 1 jumantik untuk melakukan PSN yang tepat sasaran yaitu memantau secara rutin kondisi sumur dengan funell trap dan menutup sumur setelah digunakan agar tidak menjadi tempat yang berpotensi bagi nyamuk untuk berkembangbiak

\section{UCAPAN TERIMA KASIH}

Dinas Kesehatan Kabupaten Klaten, Puskesmas Gergunug, dan seluruh pihak yang telah mendukung jalannya penelitian in dan Kemenristek Dikti yang telah membiayai penelitian ini pada tahun anggaran 2017.

\section{DAFTAR PUSTAKA}

1. WHO. (2016a). Dengue Control Epidemiology. Diakses pada 28 Februari 2017.

http://www.who.int/denguecontrol/epide miology/en/

2. WHO. (2016b). Dengue Data Application. Diakses pada 28 Februari. 
http://www.who.int/denguecontrol/epide miology/dengue data application/en/

3. Sariwati, E. (2017). Upaya Penaggulangan Penyakit Tular Vektor. Seminar Nasional Yogyakarta. Kasubdit Malaria. Kemenkes RI.

4. Dinkes Jawa Tengah. (2015). Profil Kesehatan Provinsi Jawa Tengah. Jawa Tengah: Dinas Kesehatan Provinsi Jawa Tengah.

5. Dinkes Klaten. (2015). Profil Kesehatan Provinsi Jawa Tengah. Jawa Tengah: Dinas Kesehatan Provinsi Jawa Tengah.

6. Puskemas Gergunung. (2017). Kasus Demam Berdarah Dengue di Wilayah Kerja Puskesmas Desa Gergunung. Klaten, Jawa Tengah

7. Ostfeld RS, Glass GE, Keesing F. (2005). Spatial epidemiology: an emerging (or re-emerging) discipline. Trends Ecol Evol (Amst). 20 (3) 328336.

8. Kemenkes RI. (2016). Profil Kesehatan Indonesia. Diakses pada 14 Maret. www.depkes.go.id/.../profil-kesehatanindonesia/profil-kesehatan-Indonesia2015.pdf

9. Kemenkes RI. (2009). Pencegahan dan Pemeberantasan DBD di Indonesia: Ditjen P2M dan PL. Jakarta.

10. Nugrahaningsi, M., Putra, N., dan Aryanta, I. R. (2010). Hubungan Faktor Lingkungan dan Perilaku Masyarakat dengan Keberadaan Jentik Nyamuk Penular Demam Berdarah Dengue (DBD) di Wilayah Kerja Puskesmas Kuta Utara. Journal Ecotrophic. Vol.5 (2) 93-97.

11. Hendri Joni, Res, Prasetyowati (2010). Tempat Perkemabngbiakan Nyamuk Aedes spp. di Pasar Wisata Pangandaran. Aspirator. 2(1): 23-31.

12. Sari, P., Martini, \& Ginanja, P. (2012). Hubungan Kepadatan Jentik Aedes sp dan Praktik PSN dengan Kejadian DBD di Sekolah Tingkat Sekolah Dasar.
Jurnal Kesehatan Masyarakat. 1 412-422.

13. Ambarita, L. P., Sitorus, H., \& Komaria, R. H. (2016). Habitat Aedes Pradewasa dan Indeks Entomologi di 11 Kabupaten/Kota Provinsi. Jurnal Balaba. 12 (2) 111-120.

14. Purnama, S. G., \& Baskoro, T. (2012). Maya Index dan Kepadatan Larva Aedes aegypti terhadap Infeksi Dengue. Jurnal Makara Indonesia. 16 (2) 57-64.

15. Prasetyowati, H., \& Ginanjar, A. (2017). Maya Indeks dan Kepadatan Larva Aedes aegypti di Daerah Endemis DBD Jakarta Timur. Vektora. 11(1) 43-49.

16. Sukesi, T. W. (2012). Monitoring Populasi Nyamuk Aedes aegypti L. Vektor Penyakit Demam Berdarah Dengue di Kelurahan Gedongkiwo Kecamatan Mantrijeron Kota Yogyakarta. KESMAS, 1 (74).

17. Nguyen, L A P. (2011). Abundance and prevalence of Aedes aegypti immatures and relationships with household water storage in rural areas in Southern Vietnam. Int. Health. 3 (6) 115-125

18. Lameshow dan Lwanga. (2008). Sample Size Determination in Health Studies. Software by WHO

19. Ginonar, Y. R., Rusmiarto, S., Susapto, D., Elyazar, I. R., \& Bangs, M. J. (2001). Sumur Sebagai Habitat yang Penting untuk perkembangbiakan Nyamuk Aedes aegypti. Buletin Penelitian Kesehatan, 22-31.

20. Kemenkes RI. (2011). Modul Pengendalian Demam Berdarah Dengue. Kementerian Kesehatan Republik Indonesia. Jakarta

21. Kemenkes RI. (2017). Pedoman Pengumpulan Data Vektor (Nyamuk) di Lapangan. Balai Besar Pengendalian dan Pengembangan Vektor dan Reservoir Penyakit, Kemenkes RI, Jakarta.

22. Queensland Government. (2011). The Queensland Dengue Management Plan 
2010-2015. Fortitude Valley:

Queensland Health.

23. Miller J, Martínez BA dan Gazga SD. (1992). Where Aedes aegypti live in Guerrero; using the Maya Index to measure breeding risk. In S. Halstead \& D. H. Gómez, eds. Dengue: A worldwide problem, a common strategy Ministry of Health, Mexico, and Rockefeller Foundation.

24. Ma'mum. (2007). Survei Entomologi Penyakit Demam Berdarah dengue dan Perhitungan Maya Index di Dusun Kalangan, Kelurahan Baturetno, Kabupaten BantulUniversitas Gadjah Mada Yogyakarta.

25. Ramadhani M., M dan Astuty H. (2013). Kepadatan dan Penyebaran Aedes aegypti Setelah Penyuluhan DBD di Kelurahan Paseban, Jakarta Pusat. eJKI. 1(1) 5-9

26. Dhewantara P \& Dinata A. (2015). Analisis Resiko Dengue Berbasis Maya Indeks pada Rumah PenderitaDBD di Kota Banjar Tahun 2012. Balaba. 11 (27).

27. Astuti, E. P., Prasetyowati, H., dan Ginanjar, A. (2016). Risiko Penularan Demam Berdarah Dengue berdasarkan Maya Indeks dan Indeks Entomologi di
Kota Tangerang Selatan, Banten. Media Litbangkes, 26 (4) 211-218

28. Nani. (2017). Hubungan Perilaku Psn Dengan Keberadaan Jentik Aedes aegypti di Pelabuhan Pulang Pisau. Jurnal Berkala Epidemiolog. 5 (1) 1-12.

29. Aulia, S., Djamahar, R., dan Rahmayanti. (2014). Deskripsi Tempat Penampungan Air Positif Larva Aedes aegypti di Kelurahan Cakung Timur. Jurnal BIOMA. $10(1)$.

30. Agustina, E., \& Kartini. (2017). Kajian Tempat Perindukan Nyamuk Aedes di Gampoeng Ulee Tuy Kecamatan Darul Imarah Aceh Besar. Prosiding Seminar Nasional Biotik.

31. Fauziah, N. F. (2012). Karakteristik Sumur Gali dan Keberadaan Jentik Nyamuk Aedes aegypti. Jurnal Kesehatan Masyarakat, 8 (1), 81-87.

32. Palupi Susanti Said. 2011. Survei Keberadaan Jentik Nyamuk Aedes Spp Pada Sumur gali Gali Milik Warga Di Kelurahan Bulusan Kota Semarang (Studi Di Wilayah Kerja Puskesmas Rowosari Semarang). Jurnal Kemas, 1(2) 326-337 